This is an electronic reprint of the original article. This reprint may differ from the original in pagination and typographic detail.

Author(s): Rousi, Rebekah

Title: $\quad$ Using human-values as a guide for understanding worthy design directions in augmented reality

Year: $\quad 2016$

Version:

Please cite the original version:

Rousi, R. (2016). Using human-values as a guide for understanding worthy design directions in augmented reality. In Academic MindTrek'16 : Proceedings of the 20th International Academic MindTrek Conference (pp. 243-252). Association for Computing Machinery (ACM). https://doi.org/10.1145/2994310.2994322

All material supplied via JYX is protected by copyright and other intellectual property rights, and duplication or sale of all or part of any of the repository collections is not permitted, except that material may be duplicated by you for your research use or educational purposes in electronic or print form. You must obtain permission for any other use. Electronic or print copies may not be offered, whether for sale or otherwise to anyone who is not an authorised user. 


\title{
Using human-values as a guide for understanding worthy design directions in augmented reality
}

\author{
Rebekah Rousi \\ University of Jyväskylä, Finland \\ PO Box 35 \\ 40014 University of Jyväskylä \\ +358408053100 \\ rebekah.rousi@jyu.fi
}

\begin{abstract}
Augmented reality is a fast developing field, which will no doubt gain strong footing in the area of social media in the near future. Recently, Google Glass placed AR towards the top of the technological hype curve in regards to interaction possibilities, information overlay, information search and recording. Questions still remain however, regarding the added-value that AR offers to already existing interaction modes and technologies. In this study four concepts were designed and tested via video scenarios. The concepts related to three main product categories: educational tools; information presentation; and x-ray vision. The results positively reflected on the application of AR for educational purposes and AR in navigation is also a perceived benefit. Participants projected distrust towards several points including: privacy, human-to-human interaction and safety. The findings indicate key areas of interest for development and raise questions to be dealt with relating to interaction outcomes and consequences.
\end{abstract}

\section{CCS Concepts}

- Human-centered computing $\rightarrow$ Human-computer interaction $(\mathrm{HCI}) \bullet$ Interaction design $\rightarrow$ Scenario-based design.

\section{Keywords}

Values; Augmented Reality; Human Factors; Design; Scenarios; Life-Based Design.

\section{INTRODUCTION}

Augmented reality (AR) has been actively thought about, planned, developed and experimented with for the best part of half a century. The idea of extending the real world through added vision and sound has coincided with developments in wearable computing. Notably, Morton Helig is known as a pioneer in AR and virtual reality in general (VR) for developing his machine, the Sensorama in 1957 [1]. This device was intended to give an engulfing cinematic experience, by appealing to multiple senses through the blowing of wind, sounds directed at the eyes and sides

Permission to make digital or hard copies of all or part of this work for personal or classroom use is granted without fee provided that copies are not made or distributed for profit or commercial advantage and that copies bear this notice and the full citation on the first page. Copyrights for components of this work owned by others than ACM must be honored. Abstracting with credit is permitted. To copy otherwise, or republish, to post on servers or to redistribute to lists, requires prior specific permission and/or a fee. Request permissions from Permissions@acm.org. AcademicMindtrek'16, October 17-18, 2016 Tampere, Finland

(C) 2016 ACM. ISBN 978-1-4503-4367-1/16/10 ..\$15.00

DOI: http://dx.doi.org/10.1145/2994310.2994322 of one's head, and of course vibrating seats. Jump forward several decades to 1980 and we see the development of Steve Mann's Digital Eye Glass and the subsequent EyeTap [2]. This device resembles the empty frame of a pair of glasses with the exception that a small camera and screen is placed over one eye. The camera was designed to record everything as the eye sees it, and the screen displays computer-generated imagery superimposed onto the natural scene [3]

The resemblance between EyeTap and the once highly publicized Google Glass is unmistakable. If media hype is not enough to gain the attention of technology enthusiasts, then visiting the Google Glass website [4] should be. Formerly, viewers were presented with images of extreme sports, lively cultural events, and significant milestones captured through voice activated video clips. There was also promise of Google search functions, navigation assistance and communication. Currently, the Google Glass website sports the statement: "Thanks for exploring with us - the journey doesn't end here". Emphasis within the current pages is on Google Glass application in work environments and company partners are presented from industries spanning from medical and healthcare to art and culture [5]. Thus, these pages allude to the added-value AR has in the areas of medical and healthcare, as well as e.g., culture, and even education. However, the driving factor behind this study was what the added-value of $\mathrm{AR}$ would be in people's everyday lives. Further, and more importantly, how do the qualities of AR and its understood application potential coincide with people's life values? That is, the issues and aspects people consider important in the context of their lived experience,

This was the starting point of the study discussed in this paper. The study took place in Australia and focused on AR as a concept, examining participants' familiarity with its various technological types, how they imagined it currently works and could work in the future, and how they perceived four AR application concepts. The paper progresses in the following way: firstly, related work is presented - studies presented here give examples of exploratory and user-centered design engagement, while demonstrating the need to delve deeper into the issue of examining AR through a more rigorous life-based [6] lens in order to understand the nature of values and the consequences in human-technology interaction; secondly, life-based design is introduced and through this the traditions and intentions of using a scenario-style method in exploring human values; thirdly, the empirical design is presented; and finally the results are discussed. The discussion synthesizes the findings with possible design implications, which are furthered in the ponderings featured in the conclusion.

\section{RELATED WORK}

AR research and development is a vast area, often dominated by technical papers on hardware development (output devices such as 
displays, e.g. [7]), coding and algorithms for tracking and virtual rendering $[8,9,10]$. There is also research exploring AR's potential [10]. Attention has been drawn to the relative lack in studies focusing specifically on user acceptance, user expectations and user experience in this area $[11,12,13,14]$. Furthermore, when considering user studies, studies have mostly focused on specific devices and applications, to be used in particular use contexts, often with standard user groups (e.g., university student participants, ages 18-35). Many of these studies examine task performance, cognition, perception and other usability issues [12, 15, 16]. As Thomas Olsson and colleagues [13] point out, userrelated AR studies generally focus on usability, often applying conventions and methods which were created for the evaluation of other systems, which vary in nature. Thus, there are still practical and scientific gaps pertaining to AR specific user study methodologies and techniques, and misalignments with unquestioningly applying established user-study methodologies straight to the AR domain. Furthermore, concept-level system evaluation of $\mathrm{AR}$, as well as virtual reality (VR) for that matter, remains a rarity in design and academic discourse [17]. Moreover, the conceptual examination of AR through genuinely humandriven (user-originated, genuine needs-based) concerns and values is even rarer.

Over the past few years there have been several cases in which user experience scenarios have been applied as a technique to examine the potential user experience of AR. Notably, Olsson and Väänänen-Vainio-Mattila [17] used scenarios and background research as a means of ascertaining the essential components of AR, or more specifically mobile augmented reality (MAR). These components are: 1) mobility; 2) context-sensitivity; 3 ) embedded information; and 4) AR output (p. 2). Olsson and associates [13] continued this examination through utilizing the scenario evaluation of MARs in order to identify and elaborate user concerns or risks perceived by users in regards to the technology. In this instance, users were found to exhibit distrust towards MAR in terms of a perceived flood or overload of information. Likewise, there was concern for what users felt would be a loss of autonomy and a fear of the virtual world replacing the real. Their research uncovered a correspondence between the participants' level of technological orientation and the way they accepted the scenarios.

Their studies correspond with this current study on three levels: firstly, the use potential of what AR applications may enable; secondly, key participant concerns such as distrust also arose, yet from differing perspectives; and thirdly, a noticeable pattern in participant responses depending on not only their technological experience, but also age was observed. Over and above what has often been discussed in related literature, is that the use of scenarios in a study such as this, which examined the possible application of $\mathrm{AR}$ and user experience on a conceptual level enables insight into not simply the usage value of the technologies being developed, but the added value - identifying areas in which participants see this technology offers benefits that previous technologies have not been able to.

On this note, McNaney et al. [18] explore the acceptability of Google Glass in the everyday life situations of people suffering from Parkinson's disease. While not specifically employing scenarios in their efforts, McNaney's research group examine the concrete potential of this wearable AR device with a specific user group often excluded from many user studies. Their study is relevant to this paper, in that some of the core findings such as trust (confidence), safety and security and more pertinently privacy were issues that arose in the contextual-level study. These were accompanied by the concrete findings of usability issues such as flawed voice recognition and unexpected ON/OFF periods with the device - technological limitation issues which were also identified on the contextual level by one of the participant groups observed in this present study.

\section{LIFE-BASED DESIGN AND VALUES}

Life-based design (LBD) is a framework, approach and philosophy in which all designs, technological and otherwise, should be inspired by and initiated from the potential end-users themselves $[19,20]$. The main tenet behind LBD is that humans develop technology in order to improve the quality of everyday life, and/or to free people from the arduous, less important tasks, e.g., washing clothes or bookkeeping, in order to concentrate on the more significant activities such as family life or innovating [6]. In order to achieve this effectively, designers, engineers and even researchers need to study and understand several components: people in differing life situations and states (forms of life); everyday lived experience and daily routines (rule following actions); where technologies come in handy in everyday life and what types are used (technology supported actions); and how well specific technological devices and solutions suit specific tasks and life situations (fit for life) [21].

Fit for life analysis (FfL) takes into account three main factors: 1) biological - age, gender, mental and physical health, and living environment; 2) psychological - personality, emotions and motivation, cognitive capacity, self-efficacy and coherence; and 3) socio-cultural - values, goals, attitudes, participation, social networks, education, employment as well as regulation and legislation [21]. At the heart of the FfL analysis rests the concern for ethics and morals, particularly in light of the issues faced through the above mentioned factors. Especially in consideration of HCI design and research, the idea is to gauge moral and social norms regarding and surrounding information technology design, in order to both reinforce positive influences, and counter negative ones as seen in some of the examples mentioned in the results.

The current study adopted this mindset when employing scenarios to explore how, what, where and why specific AR application concepts would fit specific forms of life. Most importantly, through especially focusing on the fit for life component, we isolated the life values of participants. These life values are seen as a means for determining indicators for predicting quality of life as participants perceive it [22]. Value in itself has been defined by the Oxford English Dictionary as the "[w]orth or quality as measured by a standard of equivalence [23]. Within the design, systems engineering, economic and information systems spheres, value-driven (value-centric) design treats values as worth, or what is worthwhile in light of investing time, money and energy in terms of motivating people to commit $[24,25,26]$. The value rests in enduring characteristics of the artefacts, services or systems which are recognized throughout the development process. These characteristics instill longevity and relevance from product launch onwards.

In information systems Cronk and Fitzgerald [27] characterize the dimensions of business value as: 1) system-dependent; 2) userdependent; and 3) business-dependent. Users, their needs and desires are the key elements for business value creation [24, 27]. In terms of a more applied framework for human values in consumption, Sweeney and Soutar [28] present a multiple item scale which includes the dimensions of: emotional value, social value, functional value (price and value for money), and functional value (performance and quality of device and function). Furthermore, their work builds upon that of Sheth et al.'s [29] 
perceived value scale, with the exception that Sweeney and Soutar separate functional value into two distinct components: economicbased on the one hand, and design-based on the other.

While the above mentioned studies are important contributions to the field, for this study we chose to focus on exploring values in relation to life and lived experience, through the LBD framework. Observing the role of technology and how it is considered in the context of people's everyday lives and how they imagine the future, and how the LBD framework can be used as a tool to gauge these values, and worthwhile directions for future (product, service and system) design practice. From an LBD perspective, user values are viewed in light of the value, or positive enhancement, that technologies can give to everyday life [19]. Thus, through LBD the significance of designing for value expands from a multi-dimensional approach to looking at value from an information systems and economic perspective (savings and increased profit margins through efficiency, value-for-money and performance) [27], to looking at a mutual value relationship between improving life quality - supporting and enhancing human values - while improving business through better solutions. For this reason, ascertaining the life values held by people, through simulated life situations (i.e. scenarios) is beneficial during the conceptual design phase [30].

\section{SCENARIOS}

Scenarios provide a detailed and flexible means of gaining insight into people's opinions regarding not just stand-alone designs, but also means and contexts in which they would desire to use various systems. Through providing a contextually based situation (problem) and narrative, people - and quite possibly, potential users - are able to clearly envision the meaning of the technologies in question. This is due to the fact that via these scenarios the conceptual artifact or system is supported by the actions, applications, context and temporal qualities of the conceptual usage situation [31, 32, 33]. As Carroll [31] quite simply puts it, "[s]cenarios are stories" which focus on people and their actions. Furthermore, the more realistic or mundane the scenario, particularly those which illustrate familiar everyday problems, the better in terms of gaining the identification of scenario study participants. That is, if they can actually envision themselves in the unravelling situations and stories, they are more likely to be able to experience the designs in question on a personal level, through drawing on past experiences.

In fact, large corporations such as Google have caught onto the value of scenarios, in offering potential customers a glimpse at spectacular experiences and events, through their online campaigns. When visiting the Google Glass website in 2013 [4] viewers were able to follow the "Explorer Stories". These stories featured anything and anyone from mothers recording their child's birthday party, through to mountain climbers. The "Explorer Program" was a collection of individual stories expressing how Glass had been used to experience events within and beyond the boundaries of everyday experience. While the current Google Glass website is mostly directed towards developers [5], one could say that a major function of $A R$ is to deliver scenarios in an overlaid manner - offering alternatives to the present lived reality. This is seen in advertising campaigns (e.g., Pepsi, Coca Cola, L'Oreal, see the Forbes article on L'Oreal AR at [34]). Thus, scenarios operate on two distinct levels in the development of AR: to observe possible applications and value-based reasoning; to understand how they afford insight into alternative scenarios through which AR may be beneficial.

\section{EMPIRICAL DESIGN}

While planning possible scenarios for this study, several AR application ideas were inspired by some of the developments taking place by programmers at the AR Lab in question. The developments were programs which focused on: 1) information display during mobile and wearable usage; 2) marker-free tracking; and 3) x-ray vision. The collection of ideas was sketched into preliminary storyboards. These storyboards were reviewed by the lab's AR developers, which were subsequently rejected, modified or accepted for video scenario building. In the end, four videos of storyboard-like scenarios were created based on applications representing three software developments: 1) educational tools for speech development; 2) information display for navigation; and 3) sensory extension (x-ray vision). Each of the videos was narrated by the researcher (recorded on video) to give a more didactic, personalized account of the application contexts, situations and potential users.

The research design itself comprised three core components: life values - a semi-structured interview component asking participants to tell about how they imagine their future will be in 10 years' time and what types of people, things and activities they would like to have in their lives during this time; AR as a concept - whether they know what AR is, how much they know and how they imagine/know it operates; and application concepts (video scenarios). This can be seen in Figure 1 .

The idea of this format was to gain an understanding of the significance, or perceived significance of AR technology to date in the life context of a cross-generational sample of people. The life values component aimed at gaining a holistic picture of the elements that were important to people, particularly in the view of future life. Responses were analyzed in light of the weighting placed on technology in relation to other elements such as family, career, hobbies etc. AR as a concept measured people's knowledge of $\mathrm{AR}$ at this point in time, probed into how they imagined it operated and also looked at how people viewed it may operate and be useful in the future. The final stage of the empirical design focused on how people evaluated the above mentioned four video scenarios of application concepts. It gauged how people emotionally responded to the scenarios, and what type of value it had in the greater life-technology ecosystems.

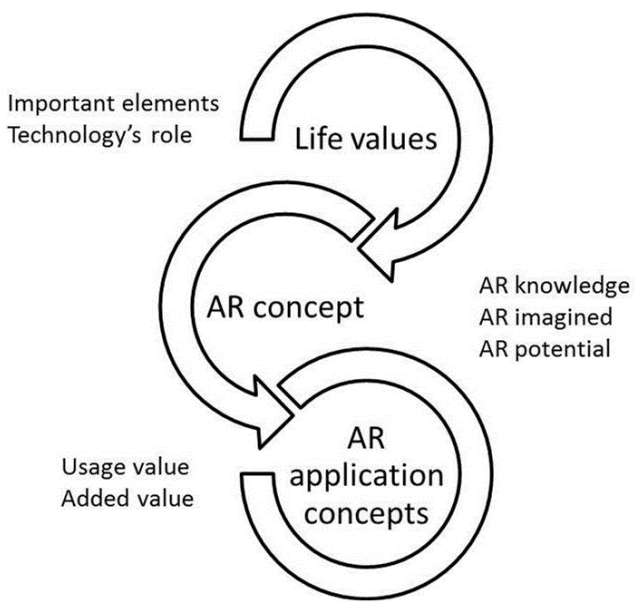

Figure 1. Empirical design progression from life picture (values) to $A R$ in life 


\subsection{Participants}

Thirty-two people took part in the study. Thirteen females and 19 males participated. The ages of the participants ranged from 22 to 71 years of age (average 40.03). The idea was to gain crossgenerational insight into opinions and views of AR and how they felt it should be developed. Professional backgrounds and overall IT orientation of the participants varied. Professional backgrounds of the participants ranged from IT specialists and researchers, to teachers, human resources management, couriers, administration and retirees. The cross-generational approach additionally offered insight into how attitudes towards technology change depending on different stages of life (mostly family and career life).

\subsection{Method}

Once the scenario videos were created, participants were recruited through word-of-mouth within the university, as well as via contacts external to the institution. When in the interview setting, participants were asked to read information about the study, which was titled the "Future Scenario Study" and sign a form of informed consent. In addition to this, participants provided background information including: gender, year of birth, nationality, native language, highest level of education achieved, professional field, and employment status.

The interview sessions began with a discussion about the participants themselves, and how they envisioned their life in 10 years' time. The aim was to develop an understanding of the participant's values (the more important things in life) and prioritizations. This component focused specifically on life values, yet it implicitly gauged how they placed technology and its development in relation to other elements of life. The next section focused explicitly on technology and how participants perceived it could be used to enhance life quality, and what types of technologies would do this. After this initial stage of attaining an understanding of the participants' views on technologies and their developments in relation to life, the interview moved on to AR. Firstly, participants were queried about their familiarity with $\mathrm{AR}$, whether or not they knew what it was and how much they knew. For those unfamiliar with AR developments, a brief description was given of its general concepts, application contexts, and a demonstration was offered through the game AR Nerd Herder [35], played on an iPad. The game provided a playful way of experiencing how AR operates in mobile computing.

Given this basis, participants were asked to indicate how much they liked the idea of AR, how useful they felt AR would be in the future, and what types of application modes they could see AR as being useful for. This was followed by the viewing and rating of the four scenario videos. Scenario A presented a learning problem in which AR was used as an educational aid. Scenario B presented a solution which combined information display with contextually aware navigational assistance. Scenario $C$ and $D$ both presented problem solutions utilizing sensory extension (x-ray vision). Figure 2 shows the problems that each of the scenarios began with, before presenting the conceptual solution.

The scenarios were shown in random order to ensure that the arrangement of the scenarios did not influence the results. One by one, participants viewed the scenarios giving an opinion rating of the concept, and then qualitatively reasoning their opinion in light of possible improvements, other uses for the software in question, and the novelty of the ideas.

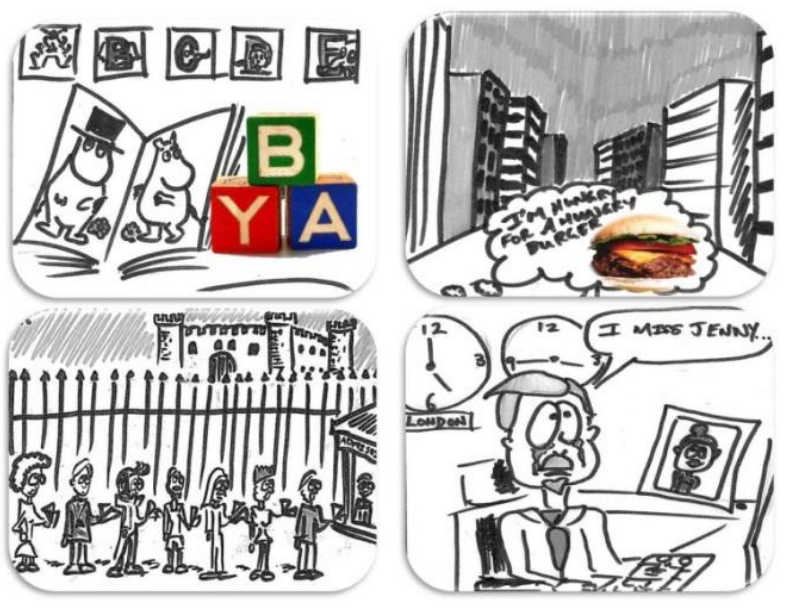

Figure 2. Presentation of problems in each of the scenarios Talking friend (upper left); Label App (upper right); X-ray Tourist (lower left); X-Ray Wall (lower right).

\subsection{Results}

The results were multi-faceted beginning with the life specific component, which progressed to the systemic view on the weighting and role of technological development in the perspective of future life quality. This was followed by participant inquiry of $\mathrm{AR}$ on a general level, and ending with specific reactions to the application concept scenario stimuli. Thus, the results are broken down into common themes of: 1) life values in the context of life circumstances; 2) technology's significance in the context of life; 3) perspectives on AR; and 4) reactions to scenario stimuli.

\subsubsection{Life values in the context of life circumstances}

This theme covers the breakdown of values expressed in participants' responses related to how they saw their ideal lives in 10 years' time. The values were sorted into five main focus categories (see Figure 3): technology 44\% (14), family and friends $34 \%$ (11), health 10\% (3), hobbies 6\% (2) and career 6\% (2).

The technology focus in describing what type of life the participant wants in 10 years' time was dominated by individuals in their twenties and early thirties, regardless of gender. Additionally, this focus was not dependent on professional background, as participants who emphasized their desire to be "surrounded by information", have "easy access to information" and to "constantly be connected" were from a range of professions including IT, engineering, teaching and hospitality. Likewise, emphasis on the value of family and friends was not dependent on professional background, but could be seen more clearly in responses by older study participants. In particular, older participants (both male and female) nearing retirement or already retired expressed the importance of family and activities which brought them closer to family and friends. Emphasis on health was not reliant on professional background, yet was connected to personal experience with family, friends and through their own health situation. Hobbies (mainly physical and outdoor) were interestingly emphasized by the older group, regardless of professional background. Career was particularly the focus of two young female participants, both teachers. 


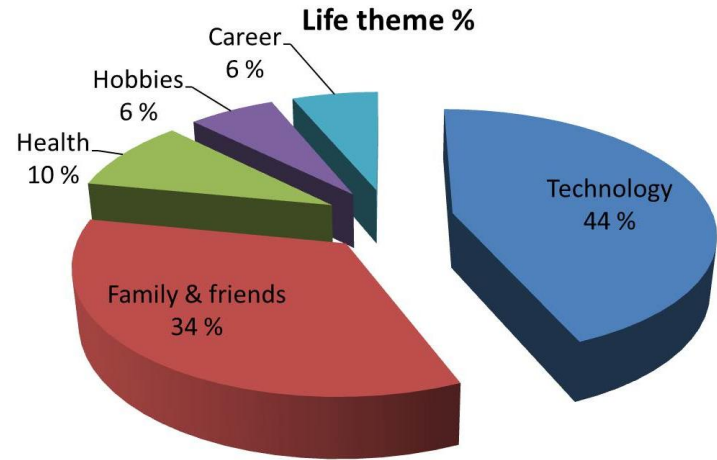

Figure 3. Five values categories according to percentage.

\subsubsection{Technology's significance in the context of life}

There were three noticeable approaches to the significance of technology in future life, as well as three distinct attitude types. Firstly, the technology approaches were sorted into the following three categories: 1) connectivity to information; 2) connectivity for communication; and 3) technology for health. It was hypothesized prior to the study that participants would perhaps raise other technological developments such as domestic robots, autonomous cars and the like, but focus was placed on connectivity, information, communication and health assistive technology. The three attitude types, once again were regardless of profession or in fact knowledge of IT developments - as there were experts and non-experts who expressed the same concerns. These were divided into: 1) techno-enthusiasts - positive regarding the benefits of technological development particularly in light of information access, ranging from 22 to 35 years of age regardless of gender; 2) informed critics - individuals (professional and non-professionals) aware of technological developments who were skeptical towards the quantities of information accessed and in particular, the dis-embodied nature of people's involvement with this information through AR or otherwise, ranging from 36 to 66 years of age, and male; and 3) skeptical critics - mainly older women who were resistant to new developments, claiming satisfaction with already existing and owned technologies, ranging from 40 to 71 years of age. These can be seen in Figure 4.

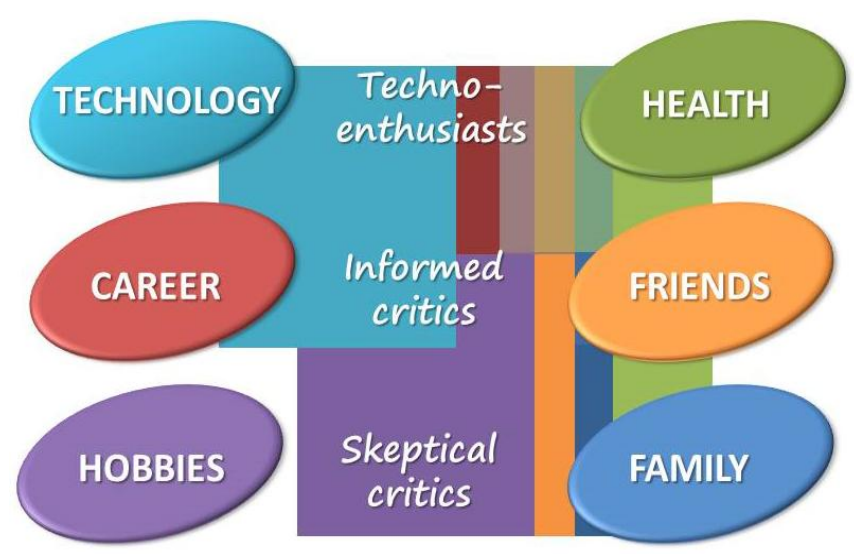

Figure 4. Life values by techno-attitude types
The life values linked to the respective attitude types are most likely not the participants' only interests and values, yet they are the first ideas and directions that came to mind when asked where they saw themselves in 10 years' time. For instance, younger participants in the technology enthusiasts group were married, had or were having children and presumably find friends and hobbies important, and for this reason they are also linked to these values, yet via the translucent shading. The results here reflect constructs (words and ideas) that first came to mind in the participants' responses when asked about how they could see their lives in 10 years' time.

As seen in the diagram, health (in green shading) was important for all the attitude types. Thus, good health was mentioned by all the participants regardless of techno-attitude type. The importance of family, friends and hobbies was expressed mostly in the responses of participants classified in the categories of Informed and Skeptical Critics. Technology was articulated in the descriptions of participants categorized under the TechnoEnthusiast and Informed Critics groups. And, career was only mentioned by those adhering to the techno-enthusiast group.

\subsubsection{Perspectives on AR}

Perspectives towards the concept of AR in general, reflected the results seen in relation to the role of technology in people's lives. Most of the participants were already aware of AR and its purpose of extending the real world through the virtual. This even applied to those who were not so familiar with the term "augmented reality" itself, but were aware of some application modes such as heads up displays in cars. The demo game of Nerd Herder [35] functioned as an introduction to AR for those more or less unfamiliar with the concept. This demo had both positive and negative consequences. On the one hand, the novelty effect of luring virtual office workers (nerds) from one side of an office to another via a fishing line and donut bait over a regular table top (albeit the printed paper game layout), was entertaining. On the other hand, the usability issues contributing to the experience of lack of control and awkwardness in using the iPad as an embodied input device were detrimental to the experience.

General unstimulated impressions of how useful participants could see AR as being in the future and what type of role the technology would play, followed in the pattern of the respondent types and life concerns, only this time profession played a greater role. IT professionals (a mixture of the informed critics and technology enthusiasts) saw AR as coming to play an important role in human-computer interaction, whereby it would replace more traditional 2D or screen-based interactions, becoming more integrated into the everyday environment in general. For some, particularly younger participants, the prospect of continually flowing, contextually aware information was exciting, and for more senior, male participants, this prospect was also alarming, as they feared the likelihood of social disengagement. On this note, yet from the opposite perspective, special education teachers (a mixture of technology enthusiasts and skeptical critics) saw the potential benefit of AR as possessing the capacity to re-engage or initiate students suffering from social disengagement into social learning situations. Three special education teachers especially including two more senior female teachers (skeptical critics) who were rather reluctant towards these technological developments saw AR technology as a means of involving students with particularly autism, Asperger's and additionally various other types of disorders such as Aphasia (affecting cognitive linguistic processes) into the social learning environment. Due to the 
significance of this finding, the prospective educational function of AR will be discussed again shortly.

Surprisingly, the AR developers (the IT professionals - i.e., Informed Critics) of mixed ages, and more senior female participants (regardless of profession - Skeptical Critics), were the most critical in terms of worthiness or added value that this mode of technology can offer over already existing technological modalities. Both groups posited that they were already satisfied with what their everyday technologies could do for them. These groups did not place the value in the technologies themselves, rather preferring life, hobbies and relationships around the technological developments. Furthermore, the developers in particular were of the opinion that with the current state-of-art in IT infrastructure (particularly bandwidth possibilities), the addedvalue which could be obtained through naturalistic, haptic and other multi-sensory interactions, would not yet be realistically feasible - even within the space of 10 years. It was instead, the technology enthusiasts, who once again envisioned their lives as being surrounded by easily accessed, tailored streams of information who could see this reality occurring. This was seen as an extreme benefit by the young teacher participants, who could imagine answering student queries, accessing performance statistics and personal information of students, as well as delivering lessons through the view of head mounted displays.

In fact, upon asking participants to rate the benefits that they felt AR would have in the areas of shopping, travelling and education, education received the highest average rating $(4,66)$ out of 5 with the lowest Standard Deviation (SD, 0,64). This was followed by travelling (average 4,56, SD 1) and shopping (average 3,97, SD 1,13). These values can be seen in Figure 5. AR as an educational tool seemed not only the least problematic of the application concepts at this stage of the study, but also the line of application in which participants could most clearly see the potential usage and life value. Already at this stage of the study, participants began citing the benefits of $\mathrm{AR}$ in relation to the visualization and reconstruction of historical events, artifacts and nonvisible physical phenomena (such as magnet fields). Further, the idea of virtual information overlaying the real was appealing to particularly teachers, who had already encountered many problems in students' current everyday lives, such as screen dependence. Screen dependence was a troubling concern for the teachers interviewed. One teacher in particular described a scenario which demonstrated the disconnection students experienced between screen and video representations and their physical reality - that is, not recognizing their own classroom teacher who was physically in front of them, while they watched a video featuring this same teacher.

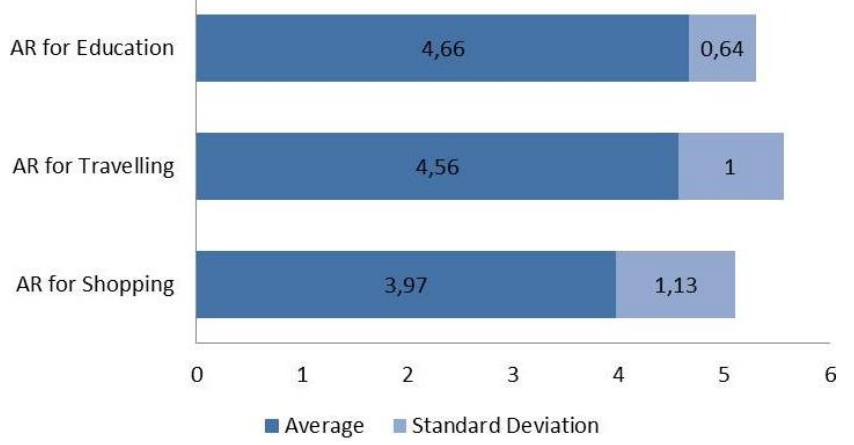

Figure 5. Rating of AR applications in the areas of education, travel and shopping

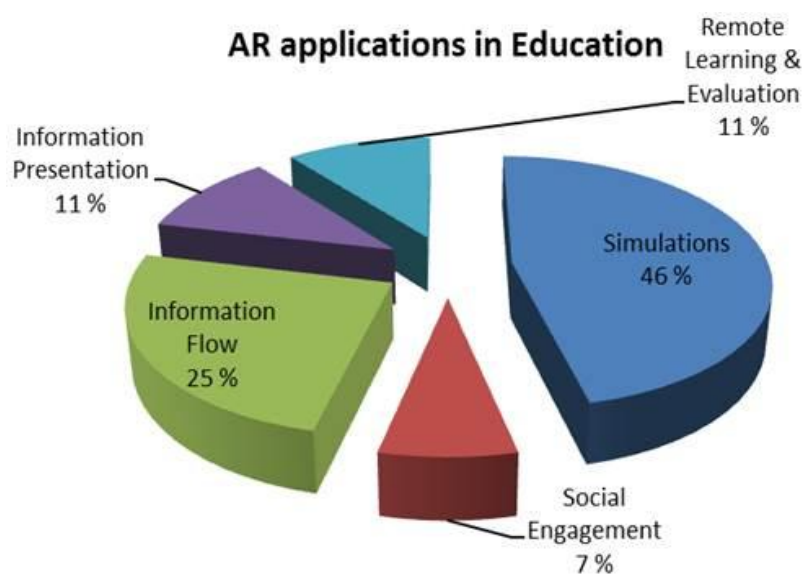

Figure 6. Distribution of suggested applications for AR in education

The positive and fairly consistent response towards the application of $\mathrm{AR}$ in educational settings calls for further attention. For this reason, the next sub-section illustrates the types of application suggestions mentioned in relation to its application.

\subsubsection{AR in education}

Based on previous research findings [36, 37, 38], it was anticipated that the use of AR in education - with or without teacher participants - would be an issue raised in discussion. Thus, the study comprised a questionnaire section focusing on the use of $\mathrm{AR}$ in education. It was at this point that even the more critical of participants began to cite the advantages. Out of the 32 participants, there were 29 suggestions for how AR could be used in education. These suggestions can be broken down into five main categories: 1) simulations; 2) social engagement; 3) information flow; 4) information presentation; and 5) remote learning and evaluation. See Figure 6.

\subsection{Simulations}

The simulations category attracted the most (46\%) suggestions, of which included: a) providing students with realistic and even tangible experiences of scenarios, rare or extinct artefacts and phenomena, as well as previous eras; b) visualization of learning material and how information operates in practice; c) feelings of presence and immersion in the learning material; d) the visualization of phenomena such as magnetic fields and physics related elements, which are not necessarily visible to the human eye; e) dangerous equipment and situation training, i.e. handling of chemicals and dealing with disasters; and f) vehicle operation instruction (flying, trains, cars and other heavy vehicles).

\subsection{Information flow}

The next most popular category was information flow (25\%) which included: a) fast information retrieval; b) continuous information access; c) information filters, personalized and targeted information flow; and d) data gathering from the student's learning environment and group dynamics, e.g. in both cases of distance learning as well as classroom-based learning understanding the students' learning situations.

\subsection{Information presentation}

Information presentation (11\%) suggestions included: a) clearer presentation of information and how it relates to the lived world; b) easy-to-read, accurate and seamless integration of information 
such as maps into views of the real environment; and c) the overlaying of information and alternative views (Birdseye, x-ray etc.) onto the real environment.

\subsection{Social engagement}

Social engagement $(7 \%)$ was the final category suggested. This was suggested by two special education teachers who recognized the benefit of AR in activating social engagement with other students via the aid of specific interactive activities. Particularly concern had been expressed by both teachers regarding: a) social disengagement induced through screen dependence (excessive screen watching via television, internet or computer game consumption); and b) social isolation by those suffering specific disorders which rendered students unable to deal with everyday social situations. Thus, AR was seen as affording a middle ground between total human-screen interaction, and human-real world interaction in social settings.

\subsubsection{Reactions to scenario stimuli}

The final component of the interviews consisted of participants viewing four scenario videos. The videos were: a) Talking Friend - an AR application to assist users (children) with language and speech development; b) Labels - an environmental information overlay application providing information pertaining to the observed environment; c) X-ray Tourist - an application which allows tourists to see through the walls of major tourist attractions; and d) X-ray Wall - a telepresence application that allows loved ones living at great distances to constantly see and interact with one another as if they were in neighboring rooms.

The participant ratings of the video scenarios highly corresponded to the participant type and their technological orientations, and reflect sentiments which had been present throughout the interview situation. That is, the education-based related scenario Talking Friend received an average rating of 4,4 (standard differentiation 0,9 ) out of 5 , meaning that this was the most preferred out of the application concepts. Labels or the application of information overlaid onto the environment, specifically landmarks and infrastructural features, received an average of 4,06 (standard deviation 1,22). X-Ray Tourist received an average of 3,4 (standard deviation 1,37) and $X$-ray Wall received an average of 3,22 (standard deviation 1,54). See Figure 7.

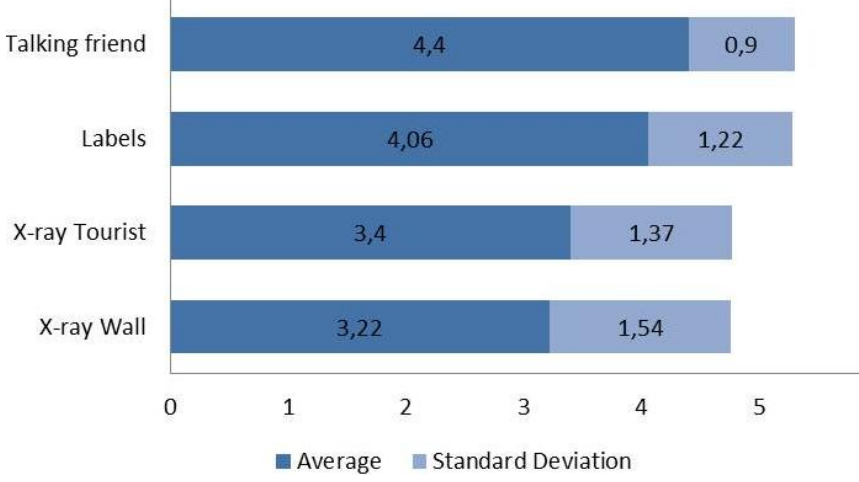

Figure 7. Rating of AR application video scenarios

\subsubsection{Talking Friend}

According to the participants' comments, Talking Friend was seen as being the most innovative and having the most added value in terms of AR application. Many of the participants reasoned their responses through mentioning personal experiences of friends and family members suffering from problems with speech and language development, viewing this application as a useful aid in both speech acquisition and even language learning. They mentioned the challenges their friends and loved ones have had in not being able to be present and attentively active to constantly stimulate language development in small children with lagging development. They mentioned that perhaps this AR application would afford the persistent attention and feedback that is needed to stimulate language and speech development.

\subsubsection{Labels}

While Labels was viewed as possessing use value in terms of easy to access directions, building names, contents and other relevant information, it was also seen as a concept similar to what is already available, in terms of Layar and other similar applications. On this note, the telepresence application of X-ray Wall was also seen as a dated concept, whereby without the extra interactive qualities of haptic sensations and smells, the application was little more than a "creepy" version of Skype.

\subsubsection{X-ray Wall}

Another factor that arose while viewing the scenarios was the matter of privacy. Both $X$-ray Wall and $X$-ray Tourist were criticized for perceived invasion of privacy. Some participants thought the idea of X-ray Wall and constantly being 'near' loved ones was a good idea, however, they would want the assurance of tight security settings. Others felt, even with loved ones, that there is value in privacy, and that they would not like family or friends to be able to see what they were doing all the time - or any of the time for that matter. This issue arose in McNaney et al.'s [18] study, whereby participants trialing Google Glass felt that family and loved ones were somehow over-using the monitoring capacity of the device to keep track of and control the participants' actions. Thus, the issues of privacy and personal solitude are also a matter to further investigate.

\subsubsection{X-ray tourist}

$\mathrm{X}$-ray Tourist was perceived as an extreme version of this $\mathrm{X}$-ray vision concept. While the intention was for tourists to be able to undertake tours in which they could see inside points of interest, from the outer peripheries - rather than queueing, paying and entering the structures physically - many of the participants interpreted this as pertaining to the ability to see inside the walls of any architectural structure. Firstly, they questioned the authenticity of visiting a location without actually physically entering - thus decreasing the experience. Further, they also felt that this type of application would surely be abused by the wrong people for the wrong reasons compromising both security and safety.

\section{DISCUSSION}

Observations of the preferences and values maintained by people in and around technology are always interesting to follow. This study revealed some profound relationships and dynamics between where participants saw value, and in what ways technology could add value to specific life situations and FoLs. One group that especially caught our attention was that of the informed critics (more senior IT programmers in particular). Their views were insightful from both the perspective of their 
understanding of the technology - its capabilities and limitations as well as where they position AR and its potential in the scheme of life. This group, while understanding the technology, its possibilities and limitations, still questioned the value of AR in comparison to genuine experiences such as authentic first person encounters - actually being there, visiting significant points of interest, meeting real people and becoming involved in acts of doing. This group of participants was additionally interested in trying new activities hands on either for educational purposes or for the sake of genuine physical experience. Their arguments were based on the value of multi-sensory experience, the types of experiences which are still far beyond mainstream AR use, i.e. full tactile sensations, smells, tastes and the aura of being there, and the ability to recall and recount to others the actual experience of visiting the location. On some levels, an important element of what Battarbee and Koskinen [39] refer to as "co-experience".

Interestingly, on a cultural level, almost one century later, this participant observation reflects much of what Walter Benjamin [40] had written regarding aura in his text The Work of Art in the Age of Mechanical Reproduction. In fact, this timely piece demonstrates the cultural repercussions of the age of mechanical mass reproduction which strongly resonate with what can be seen as happening in the age of total connectivity - fears that the virtual (or mechanical) will overtake the real, yet simultaneously reaffirmation of the real, through familiarity generated by the virtual (reproductions).

Moreover, this group of participants also expressed genuine concern regarding detachment from the real world, and in particular from other people. These participants articulated the importance of family, joint activities and hobbies (mainly physical) such as cross-country motorcycle riding and surfing, and most significantly co- or shared experiences. Ironically, it is just these are activities which were focused on in the now defunct Google Glass campaign, reaffirming the importance of the social and physical interactions in creating the user experience. These qualities are also seen as the strength in the current hit of Pokemon Go.

\section{CONCLUSION}

Amongst the hype of mobile and wearable AR development for mainstream consumption, particularly in light of defunct products such as Google Glass, and new game crazes such as Go this study has aimed to hone in on the added value, beyond other existing technologies, that these types of technology actually afford. This has been achieved through utilizing the life-based design method for examining life systems based on forms of life (life situations), and how phenomena and dimensions are valued within the schema of these systems. The study was approached on the basis of obtaining an initial life picture, of the types of issues and factors that really matter in the scope of human life values. It then looked at how people conceptually viewed AR technology - what they imagined it to be like, and how useful it would be in the future. The study then moved more specifically to exploring the application value of $\mathrm{AR}$ in the areas of education, travel and shopping, isolating education as the key area in which AR could add such added value. Progressing from this to specific questions regarding education applications of $\mathrm{AR}$, and then asking participants to rate and comment on video application scenarios of $\mathrm{AR}$, revealed two distinct attitude types: 1) technology enthusiasts; and 2) informed critics. These attitudes did not so much represent any particular level of technology experience or profession, rather, it more related to the age, or stage of life of the person in question.

Moreover, issues of trust, security, privacy, social control and engagement/disengagement which have been present in previous studies $[16,20,21]$ also arose in this study on the conceptual level. Yet, in addition to raising areas of concern related to AR, it also revealed numerous possibilities for how the mode of wearable mobile AR may be applied. It revealed the underlying values of participants in general, and how these corresponded with either the acceptance or rejection of AR application concepts, several of which have been addressed in this paper. The main purpose of a study of this nature is to reveal how technological concepts (ideas) operate and manifest not just in the minds of individuals, but also on social and cultural levels - aspirations of which research in areas such as co-experience [5] aim to achieve. LBD as a method and a philosophical approach towards understanding how diversity in relation to people, does not exist simply between people but within people, as we all change from one moment to the next. The study revealed issues of concern, life values, and values within technological concepts. And, it also revealed that through focusing on life first, as designers we can get to the heart of what really matters in relation to what we are developing.

\section{ACKNOWLEDGMENTS}

I would like to thank Christian Sandor for hosting me at the Magic Vision Lab, as well as the University of Jyväskylä and Tekes for funding this research. Prof. Pertti Saariluoma, has been the absolute best in terms of giving us the freedom to explore research possibilities with and through LBD. Finally, to all the participants and colleagues who contributed to this study, I am extremely grateful.

\section{REFERENCES}

1. Sung, D. 2011. The history of augmented reality. Pocket-lint. (Mar. 2011). http://www.pocket-lint.com/news/108888-thehistory-of-augmented-reality.

2. Mann, S. and Niedzviedcki, H. 2001. Cyborg: Digital destiny and human possibility. Double Day, Toronto.

3. Mann, S., Fung, J., Aimone, C., Sehgal, A. and Chen, D. 2005. Designing EyeTap digital eyeglasses for continuous lifelong capture and sharing of personal experiences. In Alt. CHI. Proceedings of CHI 2005 (Portland, OR, USA, April 2$7,2005)$, ACM, New York, NY.

4. Google. Google Glass - explorer stories. https://www.google.com/glass/start/explorer-stories/.

5. Google. Google Glass. https://www.google.com/glass/start/.

6. Leikas, J. 2009. Life-Based Design - A Holistic Approach to Designing Human-Technology Interaction. Doctoral Thesis, VTT Publications 726, Edita Prima, Helsinki.

7. Milgram, P. and Kishino, F. 1994. A taxonomy of mixed reality visual displays. IEICE Transactions on Information Systems E77-D 12 (Aug. 1994), 1321-1329.

8. Aittala, M. 2010. Inverse lighting and photorealistic rendering for augmented reality. The Visual Computer 26, 6-8 (Apr. 2010), 669-678.

9. Azuma, R. 1993. Tracking requirements for augmented reality. Communications of the ACM 36, 7 (Jul. 1993), 50-51. 
10. Azuma, R. 1997. A survey of augmented reality. Presence 6, 4 (Aug. 1997), 355-385.

11. Dünser, A., Grasset, R. and Billinghurst, M. 2008. A survey of evaluation techniques used in augmented reality studies. In Proceedings of International conference on computer graphics and interaction techniques. (Singapore, December 10-13, 2008), ACM, New York, NY, 5-27.

http://www.hitlabnz.org/administrator/components/com_jrese arch/files/publications/a5-dunser.pdf.

12. Gabbard, J.L. and Swan, E. 2008. Usability engineering for augmented reality: employing user-based studies to inform design. IEEE Transactions on Visualization and Computer Graphics 14, 3 (Mar. 2008), 513-524.

13. Olsson, T., Kärkkäinen, T., Lagerstam, E. and VentäOlkkonen, L. 2012. User evaluation of mobile augmented reality scenarios. Journal of Ambient Intelligence and Smart Environments 4, 1 (Jan. 2012), 29-47.

14. Swan, E. and Gabbard, J.L. 2005. Survey of user-based experimentation in augmented reality. In Proceedings of $1^{\text {st }}$ international conference on virtual reality, HCI International (Las Vegas, NV, USA, 22-27 Jul. 2005).

15. Kruijff, E., Swan, E. and Feiner, S. 2010. Perceptual issues in augmented reality revisited. In Proceedings of Mixed and Augmented Reality (ISMAR) 9 (October 13-16, 2010), 3-12.

16. Nilsson, S. 2010. Augmented in the wild: user centered development and evaluation of augmented reality applications. Doctoral dissertation, Linköping University, Linköping, Sweden.

17. Olsson, T. and Väänänen-Vainio-Mattila, K. 2011. Expected user experience with mobile augmented reality services. In Workshop of mobile augmented reality, Mobile HCI (Stockholm, Sweden, August 30-September 2, 2011), ACM, New York, NY.

18. McNaney, R., Vines, J., Roggen, D., Balaan, M., Zhang, P, Poliakov, I. and Olivier, P. 2014. Exploring the acceptability of Google Glass as an everyday assistive device for people with Parkinson's. In Proceedings of CHI 2014, (Toronto, Canada, April 26-May 1, 2014), ACM, New York, NY, 25512554.

19. Leikas, J., Saariluoma, P., Heinilä, J. and Ylikauppila, M. A methodological model for Life-Based Design. 2013. International Review of Social Sciences and Humanities (IRSSH), 4, 2 (2013), 118-136.

20. Saariluoma, P. and Leikas, J. 2010. Life-based design - an approach to design for life. Global Journal of Management and Business Research GJMBR. 10, 5 (2010), 17-23.

21. Leikas, J. and Ikonen, V. 2013. Life-based design to ensure that technology is fit for life. In M. Isomursu, M. Toivonen, M. Kokkala, and P. Pussinen, Eds., Highlights in service research, VTT Research Highlights, 6 (2013), VTT, Espoo, 23-29.

22. Carlquist, E. Ulleberg, P., Delle Fave, A., Nafstad, H., and Blakar, R. 2016. Everyday understandings of happiness, good life, and satisfaction: three different facets of well-being. Applied Research in Quality of Life (Apr. 2016), Springer, 1$25 . \mathrm{DOI}=10.1007 / \mathrm{s} 11482-016-9472-9$

23. Oxford English Dictionary. 2016. Value. http://www.oed.com/view/Entry/221253?rskey=RsKiNv\&res ult=1\#eid
24. Kujala, S. and Väänänen-Vainio-Mattila, K. 2009. Value of Information Systems and Products: Understanding the Users' Perspective and Values. J. Info. Tech. Theory and App. (JITTA). 9, 4 (Jul. 2009), Article 4. http://aisel.aisnet.org/jitta/vol9/iss4/4.

25. Cockton, G. 2006. Design worth is worth designing. (Oslo, Norway, October 14-18, 2006), ACM, New York, NY, 165174.

26. Cockton, G. 2008. Designing worth - connecting preferred means to desired ends. Interactions 15, 4 (Jul.+Aug. 2008). ACM, New York, NY, 54-57.

27. Cronk, M. and Fitzgerald, E. 1999. Understanding "IS business value": derivation of dimension. Logistics Information Management, 12, 1/2 (1999), 40-49.

28. Sweeney, J. and Soutar, G. 2001. Consumer perceived value: the development of a multiple item scale. Journal of Retailing 77, 2 (2001) 203-220.

29. Sheth, J. 1991. Why we buy what we buy: a theory of consumption values. Journal of Business Research 22, 2, 159170.

30. Herterich, M., Holler, M., Uebernickel, F. and Brenner, W. 2015. Understanding the business value: towards a taxonomy of industrial use scenarios enabled by cyber-physical systems in the equipment manufacturing industry. CONF-IRM 2015 Proceedings (Ottawa, Ontario, Canada, May 18-20, 2015), Paper 31. http://aisel.aisnet.org/confirm2015/31.

31. Carroll, J.M. 2000. Five reasons for scenario-based design. Interacting with computers 13, 1 (2000), 43-60.

32. Jumisko-Pyykkö, S., Weitzel, M. and Strohmeier, D. 2008. Designing for user experience: what to expect from mobile 3D TV and video? In Proceedings of the $1^{\text {st }}$ conference on designing interactive user experiences for TV and video (Silicone Valley, California, USA, October 22-24, 2008), ACM, New York, NY, 183-192.

33. Rosson, M.B. and Carroll, J.M. 2001. Usability engineering: scenario-based development of human-computer interaction Morgan Kaufmann Publishers, New York, NY.

34. Trefis Team. 2016. Why is L'Oreal increasing its focus on augmented reality?. Forbes (Mar. 2016).

http://www.forbes.com/sites/greatspeculations/2016/03/15/wh $\mathrm{y}$-is-loreal-increasing-its-focus-on-augmentedreality/\#7b66c07132fd.

35. Mendenhall, S., Ha, V., Tillery, P., Cohen, J., Sharp, J. and MacIntyre, B. 2012. NerdHerder: designing for physical actions in an augmented reality puzzle game. In Proceedings of the international conference on the foundations of digital games, (Raleigh, NC, USA, May 29-June 1, 2012), ACM, New York, NY, 250-253.

36. Billinghurst, M. 2002. Augmented reality in education. New Horizons for Learning 12 (2002). http://www.it.civil.aau.dk/it/education/reports/ar_edu.pdf

37. Wu, H. K., Lee, S. W. Y., Chang, H. Y. and Liang, J. C. 2013. Current status, opportunities and challenges of augmented reality in education. Computers \& Education. 62 (Mar. 2013), 41-49.

38. Yuen, S., Yaoyuneyong, G., and Johnson, E. 2011. Augmented reality: An overview and five directions for AR in 
education. J. Ed. Tech. Dev. and Exchange. 4, 1 (Oct. 2011), 119-140.

39. Battarbee, K. and Koskinen, I. 2004. Co-experience: user experience as interaction. CoDesign 1, 1 (May, 2004), 5-18.
40. Benjamin, W. 1936. The work of art in the age of mechanical reproduction. H. Zohn trans., H. Arendt ed., Schocken/Random House, New York, NY. 